\title{
Aging diagnostic probe for research on aging and evaluation of anti-aging drug efficacy
}

Zihong Li, Jie Cheng, Ling Huang, Wenxiu Li, Yuping Zhao, Weiying Lin *

Guangxi Key Laboratory of Electrochemical Energy Materials, Institute of Optical

Materials and Chemical Biology, School of Chemistry and Chemical Engineering,

Guangxi University, Nanning, Guangxi 530004, P. R. China.

Email: weiyinglin2013@163.com

*Correspondence to: Weiying Lin, Guangxi Key Laboratory of Electrochemical Energy Materials, Institute of Optical Materials and Chemical Biology, School of Chemistry and Chemical Engineering, Guangxi University, Nanning, Guangxi 530004, P. R. China

Email: weiyinglin2013@163.com. 


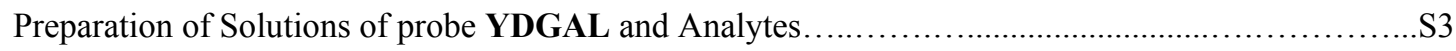

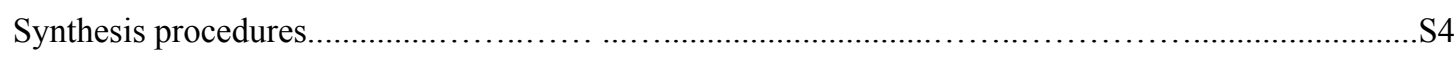

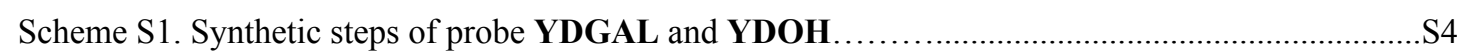

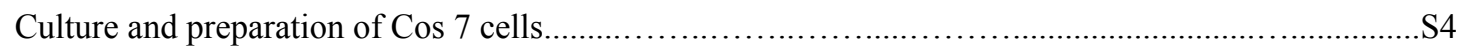

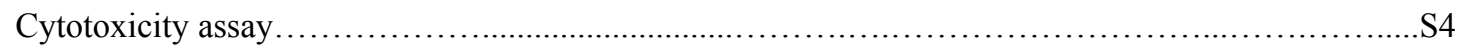

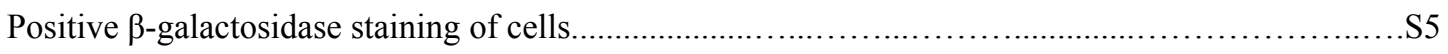

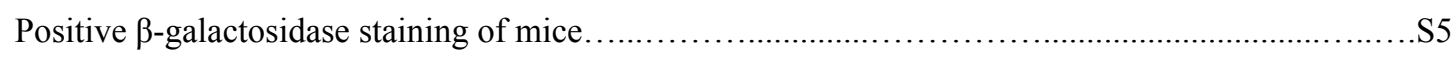

Preparation of mouse tumor slices for imaging experiments.............................................S6

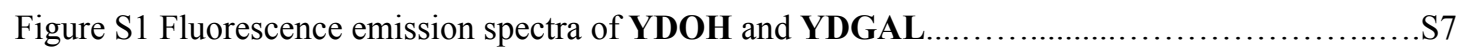

Figure S2 Time dependent of YDGAL in the presence of $\beta$-gal.......................................... 7

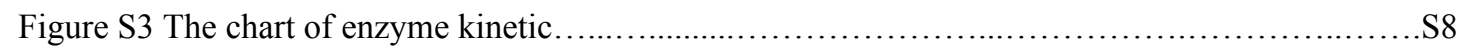

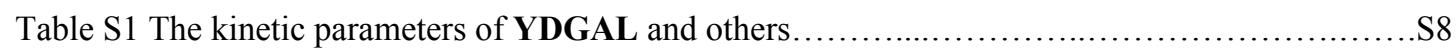

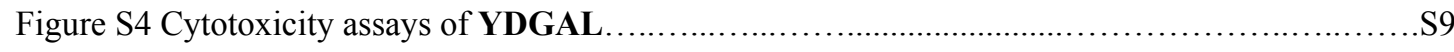

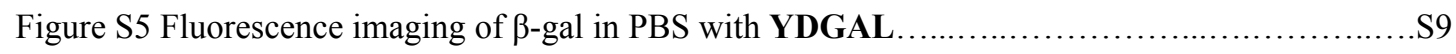

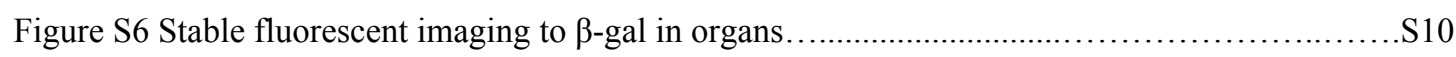

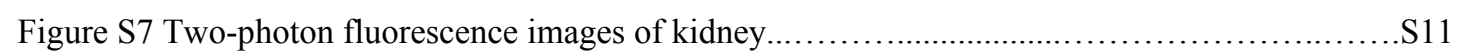

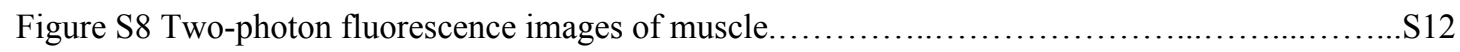

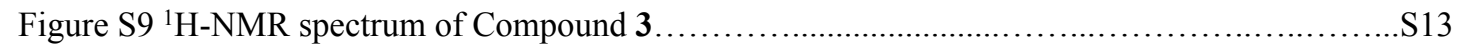

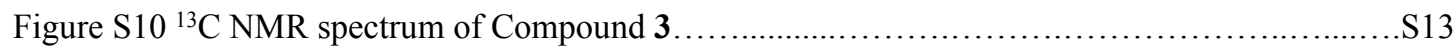

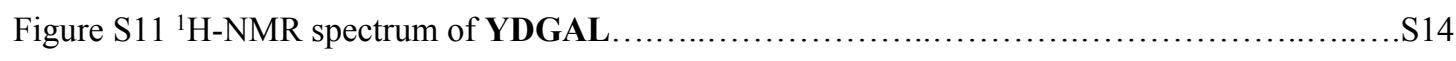

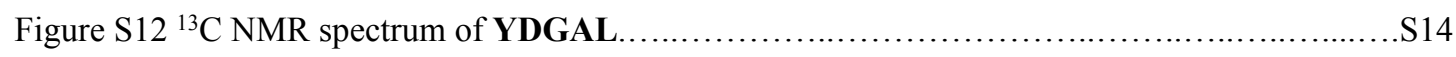

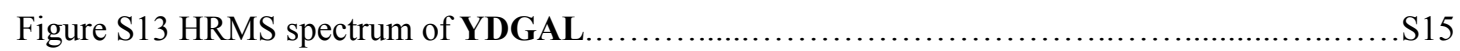

Figure S14 HRMS spectrum of the reaction products of YDGAL with $\beta$-gal.......................S15

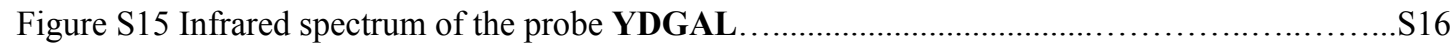

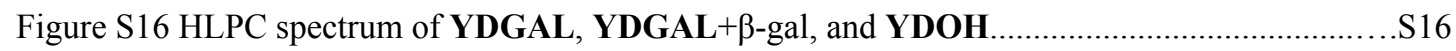




\section{Preparation of Solutions of probe YDGAL and Analytes}

Without other noted, all the tests were operated according to the following procedure. A stock solution $(1.0 \mathrm{mM})$ of YDGAL was prepared in DMSO. After adjusting the final volume to $10 \mathrm{~mL}$ with $0.1 \mathrm{M}$ PBS buffer, standing at $37{ }^{\circ} \mathrm{C} 20 \mathrm{~min}, 3 \mathrm{~mL}$ portion of it was transferred to a $1 \mathrm{~cm}$ quartz cell to measure absorbance or fluorescence. All fluorescence measurements were conducted on a Hitachi F4600 Fluorescence Spectrophotometer. The slight $\mathrm{pH}$ variations of the solutions were achieved by adding the minimum volumes of $\mathrm{NaOH}(0.1 \mathrm{M})$ or $\mathrm{HCl}(0.2 \mathrm{M})$.

\section{Synthesis procedures}

\section{Synthesis procedures of compound 1}

Dissolve p-hydroxybenzaldehyde (122 mg, $1 \mathrm{mmol}, 1 \mathrm{eq}), \mathrm{CsCO}_{3}(650 \mathrm{mg}, 2 \mathrm{mmol}$, 2 eq), $\quad \mathrm{Na}_{2} \mathrm{SO}_{4} \quad(245 \quad \mathrm{mg}, \quad 2.5 \quad \mathrm{mmol}, 2.5 \quad \mathrm{eq})$ and (2R,3S,4S,5R,6R)-2-(acetoxymethyl)-6-bromotetrahydro-2H-pyran-3,4,5-triyl (411 $\mathrm{mg}, 1 \mathrm{mmol}, 1 \mathrm{eq})$ triacetate in anhydrous acetonitrile, and stir for 24 hours at room temperature under the protection of nitrogen. At the end of the reaction, dichloromethane was used for extraction, and column chromatography (DCM/MeOH $=100 / 1)$ was used for purification. (256 mg, 56.6\% yield).

\section{Synthesis procedures of compound 2}

1,1,2-trimethyl-1H-benzo[e]indole (2 g, $10 \mathrm{mmol}$, 1eq) was dissolved in acetonitrile, Iodoethane was added and refluxed overnight. After the reaction, it was cooled to room temperature, washed out the solid, filtered and washed with petroleum ether to obtain compound 2 (1.9 g, 79.8\% yield).

\section{Synthesis of the probe YDOH.}

Add p-hydroxybenzaldehyde (122 mg, $1 \mathrm{mmol}, 1 \mathrm{eq})$ and 2 (1 mmol, $238 \mathrm{mg}, 1 \mathrm{eq})$ to absolute ethanol, and stir for 16 hours under a nitrogen atmosphere. After the reaction, it was cooled to room temperature, precipitated with petroleum ether, filtered under reduced pressure, and washed with petroleum ether to obtain a red solid, that is, the dried product. (201 mg, 53.6\% yield). 


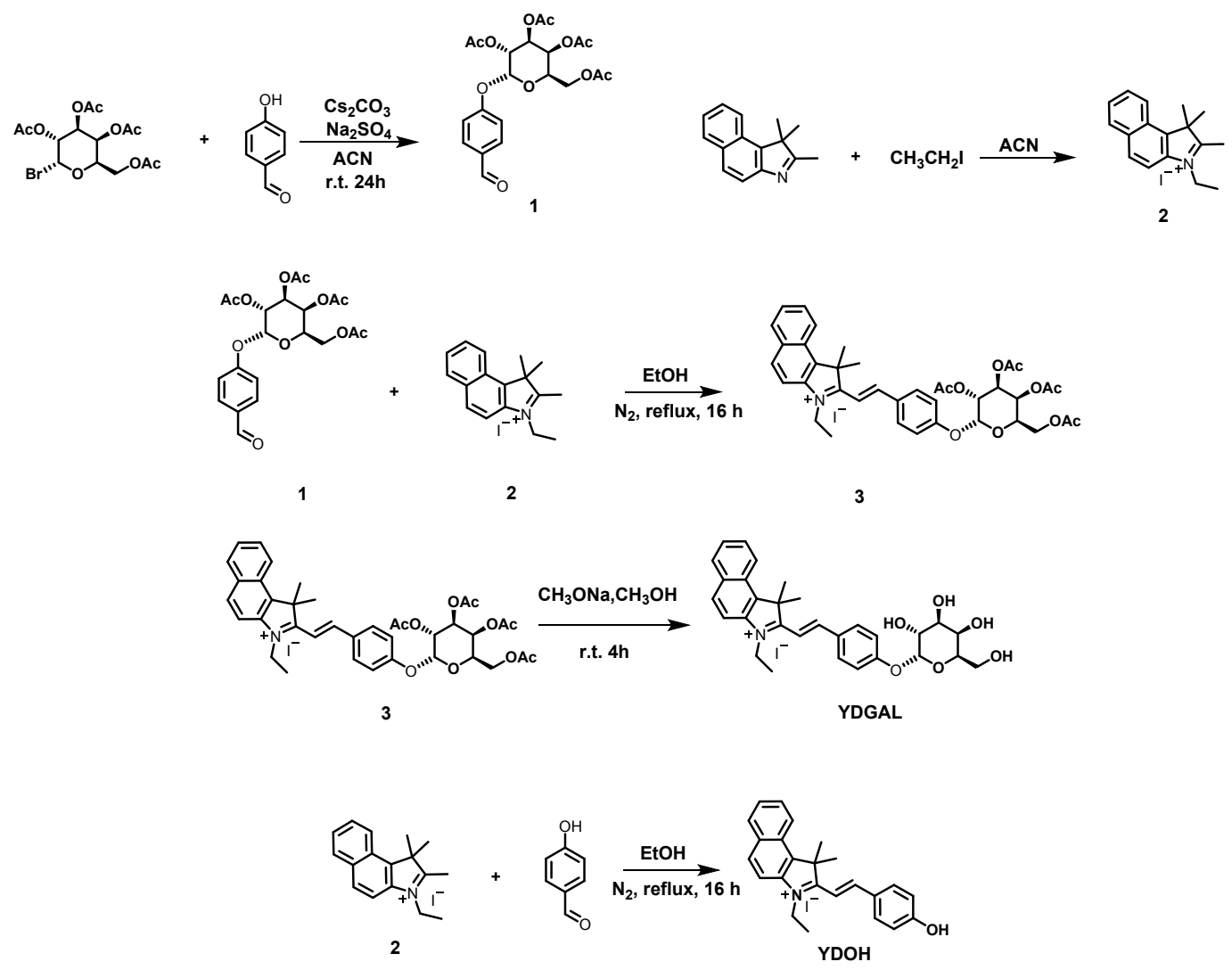

Scheme S1. Synthetic steps of probe YDGAL and YDOH.

\section{Culture and preparation of Cos 7 cells}

Cos 7 cells were cultured in DMEM (Dulbecco's modified Eagle's medium) supplemented with 10\% FBS (fetal bovine serum) in an atmosphere of $5 \% \mathrm{CO}_{2}$ and $95 \%$ air at $37{ }^{\circ} \mathrm{C}$. Before the experiments, seed the Cos 7 cells in $35-\mathrm{mm}$ glass-bottomed dishes at a density of $2 \times 10^{5}$ cells per dish in $2 \mathrm{~mL}$ of culture medium and incubate them inside an incubator containing $5 \% \mathrm{CO}_{2}$ and $95 \%$ air at $37{ }^{\circ} \mathrm{C}$. Incubate the cells for $24 \mathrm{~h}$. Cells will attach to the glass surface during this time.

\section{Cytotoxicity assays}

Cos 7 cells were seeded into 96-well plates, and $0,1,5,10,20,30 \mu \mathrm{M}$ (final concentration) of the probe YDGAL (99.9\% DMEM and 0.1\% DMSO) were added respectively. Subsequently, the cells were cultured at $37^{\circ} \mathrm{C}$ in an atmosphere of $\mathrm{CO}_{2}$ (5\%) and air (95\%) for 24 hours. Then Cos 7 cells and were washed with PBS buffer, and DMEM medium $(100 \mu \mathrm{L})$ was added. Next, MTT $(10 \mu \mathrm{L}, 5 \mathrm{mg} / \mathrm{mL})$ was injected to every well and incubated for $4 \mathrm{~h}$. Violet formazan was treated with sodium dodecyl 
sulfate solution $(100 \mu \mathrm{L})$ in the $\mathrm{H}_{2} \mathrm{O}$-DMSO mixture. Absorbance of the solution was measured at $570 \mathrm{~nm}$ by the way of a microplate reader. The cell viability was determined by assuming 100\% cell viability for cells without YDGAL.

\section{Positive $\beta$-galactosidase staining of cells}

After treating the Cos 7 cells with $\mathrm{H}_{2} \mathrm{O}_{2}$, a senescence-associated $\beta$-galactosidase staining kit (C0602, Beyotime, Jiangsu, China) was used to detect cellular senescence. Cos 7 were rinsed once with PBS or Hanks balanced salt solution (PBS) and fixed with $1 \mathrm{~mL}$ of $\beta$-galactosidase stationary liquid at room temperature for $10 \mathrm{~min}$. Then, the cell suspension underwent centrifugation, after which the stationary liquid was removed, and the samples were rinsed with PBS three times ( 3 min each time). Remove PBS, add $1 \mathrm{ml}$ of dye solution to each well, $37^{\circ} \mathrm{C}$ incubated overnight. Then the stained cells were photographed under the microscope (RVL-100-G, USA Discover-Echo, $40 \times$ ), and the aging cells turned blue.

\section{Positive $\beta$-galactosidase staining of mice}

Female Kunming mice (about 4 weeks aged) were purchased from Guangxi Medical University. The farming system of animals was under standard laboratory conditions. All animal procedures were performed in accordance with the Guidelines for Care and Use of Laboratory Animals of Guangxi Medical University and approved by the Animal Ethics Committee of Guangxi Medical University (China).

After injected D-galactose for 45 days, a senescence-associated $\beta$-galactosidase staining kit (C0602, Beyotime, Jiangsu, China) was used to detect mice senescence. The tissue pieces of kidney, spleen, and skeletal muscle were dissected from mice for aging staining. The tissues were rinsed once with PBS and fixed with $1 \mathrm{~mL}$ of $\beta$-galactosidase stationary liquid at room temperature for $15 \mathrm{~min}$. Then, the cell suspension underwent centrifugation, after which the stationary liquid was removed, and the samples were rinsed with PBS three times (5-10 min each time). Remove PBS, add $1 \mathrm{ml}$ of dye solution to each well, $37^{\circ} \mathrm{C}$ incubated overnight. Then the tissues were photographed under the microscope (RVL-100-G, USA Discover-Echo, $40 \times$ ), and the aging tissues turned blue, which proved that the mouse is an aging 
mouse.

\section{Preparation of mouse slices for imaging experiments}

Female Kunming mice (about 4 weeks aged) were purchased from Guangxi Medical University. The farming system of animals was under standard laboratory conditions. All animal procedures were performed in accordance with the Guidelines for Care and Use of Laboratory Animals of Guangxi Medical University and approved by the Animal Ethics Committee of Guangxi Medical University (China).

The slices of kidneys, spleens, skeletal muscles were prepared from the normal, senescent and treated mice, and they were cut to $200 \mathrm{~mm}$ thickness by using a vibrating-blade microtome in $25 \mathrm{mM}$ PBS $(\mathrm{pH}=7.4)$. The slices were incubated with $100 \mu \mathrm{M}$ YDGAL in PBS buffer bubbled with $95 \% \mathrm{O}_{2}$ and $5 \% \mathrm{CO}_{2}$ for $2 \mathrm{~h}$ at $37^{\circ} \mathrm{C}$, and then washed three times with PBS, transferred to the glass bottomed dishes, and observed under one-photon and two-photon confocal microscope (Leica TCS SP8 CARS confocal microscope with a $10 \times$ objective lens), respectively. The fluorescence images of the slices were acquired using 800 excitation and fluorescence emission windows of 600-750 $\mathrm{nm}$. 


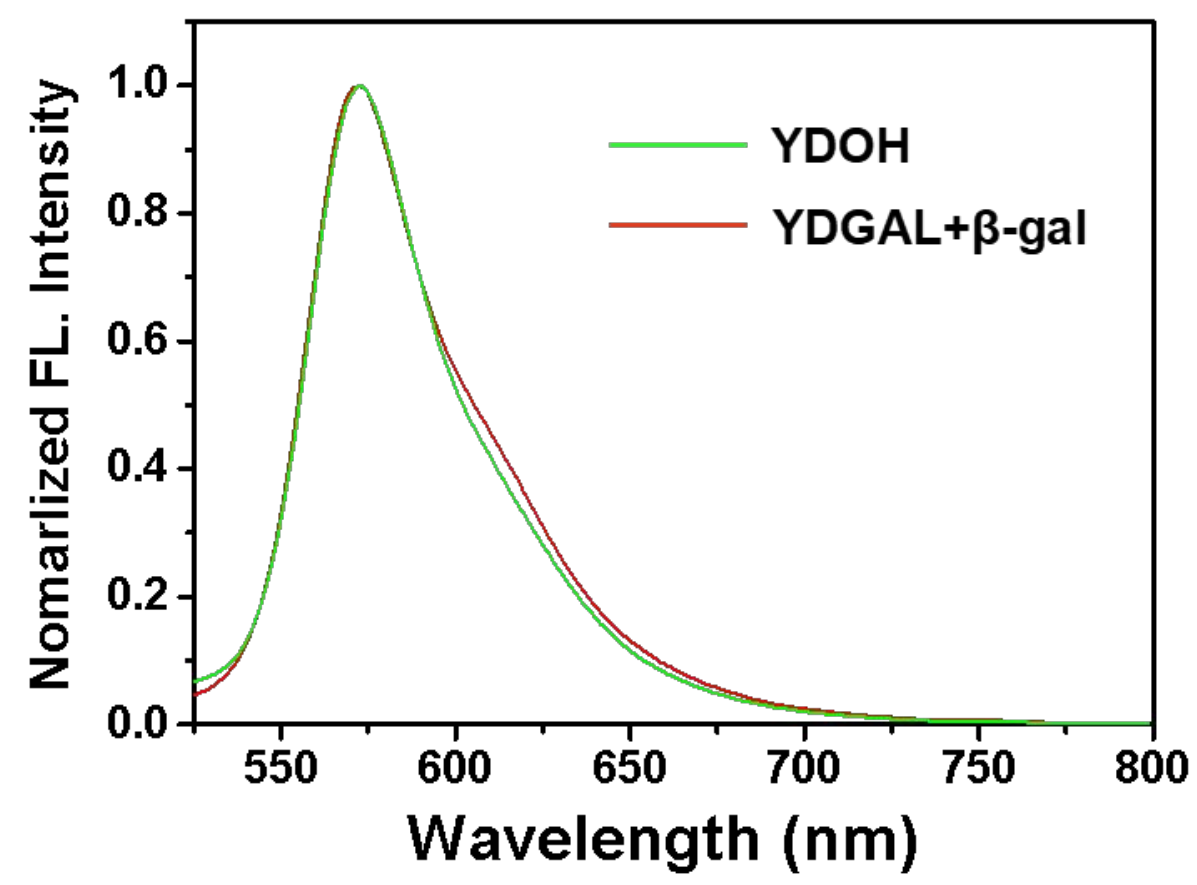

Figure S1. The maximum wavelength fluorescence spectra of of YDOH and YDGAL with or without the addition of $\beta$-gal in PBS, respectively. $\lambda_{\text {ex }}=500 \mathrm{~nm}$, Excitation Slit: $10.0 \mathrm{~nm}$, Emission Slit: $10.0 \mathrm{~nm}$.

A

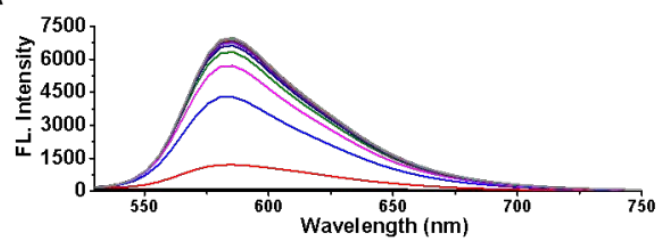

B

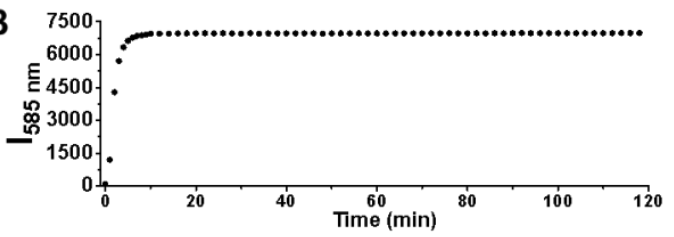

C

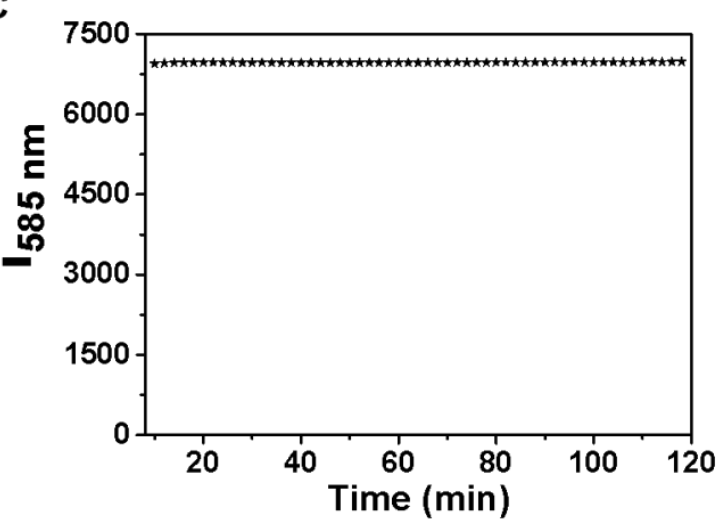

Figure S2. Time dependent of $10 \mu \mathrm{M}$ YDGAL in the presence of $\beta$-gal $(0.1 \mathrm{U} / \mathrm{mL})$ in PBS buffer (A, B) 0-120 min (C) 10-120 min. $\lambda_{\mathrm{ex}}=500 \mathrm{~nm}$, Excitation Slit: $10.0 \mathrm{~nm}$, Emission Slit: $10.0 \mathrm{~nm}$. 


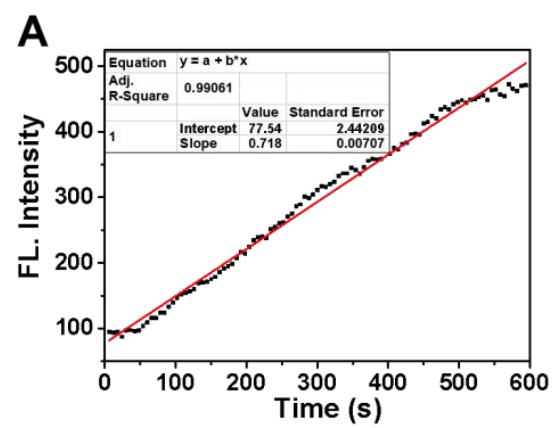

B
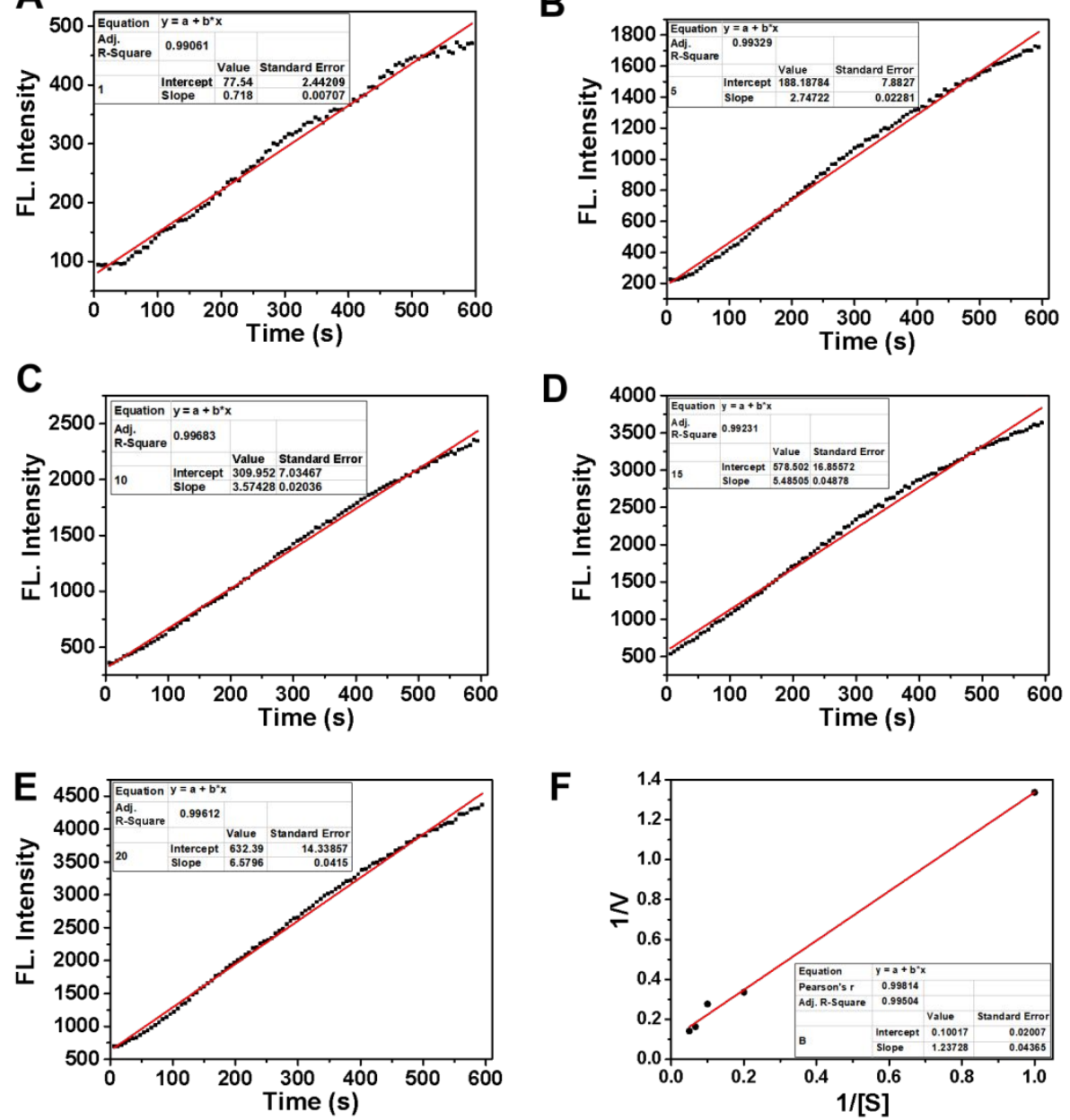

Figure S3. (A-E) The change of fluorescence intensity with time at different concentrations of substrate (YDGAL: $1 \mu \mathrm{M}, 5 \mu \mathrm{M}, 10 \mu \mathrm{M}, 15 \mu \mathrm{M}, 20 \mu \mathrm{M} ; \beta$-gal: $0.096 \mu \mathrm{M})(\mathrm{F})$ The chart of enzyme kinetics. $\lambda_{\mathrm{ex}}=500 \mathrm{~nm}$, Excitation Slit: $10.0 \mathrm{~nm}$, Emission Slit: $10.0 \mathrm{~nm}$.

\begin{tabular}{cllcc}
\hline Substrates & $\begin{array}{l}\mathrm{K}_{\mathrm{m}} \\
(\mu \mathrm{M})\end{array}$ & $\begin{array}{l}\mathrm{k}_{\text {cat }} \\
\left(\mathrm{S}^{-1}\right)\end{array}$ & $\begin{array}{l}\mathrm{k}_{\text {cat }} / \mathrm{K}_{\mathrm{m}} \\
\left(\mu \mathrm{M}^{-1} \mathrm{~S}^{-1}\right)\end{array}$ & $\begin{array}{l}\mathrm{V}_{\text {max }} \\
\left(\mu \mathrm{M} \mathrm{S}^{-1}\right)\end{array}$ \\
\hline SRP & 28.0 & $1.25 \times 10^{-3}$ & 25 & $4.5 \times 10^{5}$ \\
FDG & 10.2 & 0.156 & 0.0157 & 0.33 \\
DCM- $\beta$-gal & 60.1 & 29.19 & 0.48 & 0.54 \\
YDGAL & 12.35 & 103.96 & 8.418 & 9.98 \\
\hline
\end{tabular}

Table S1. The kinetic parameters of YDGAL and others. 


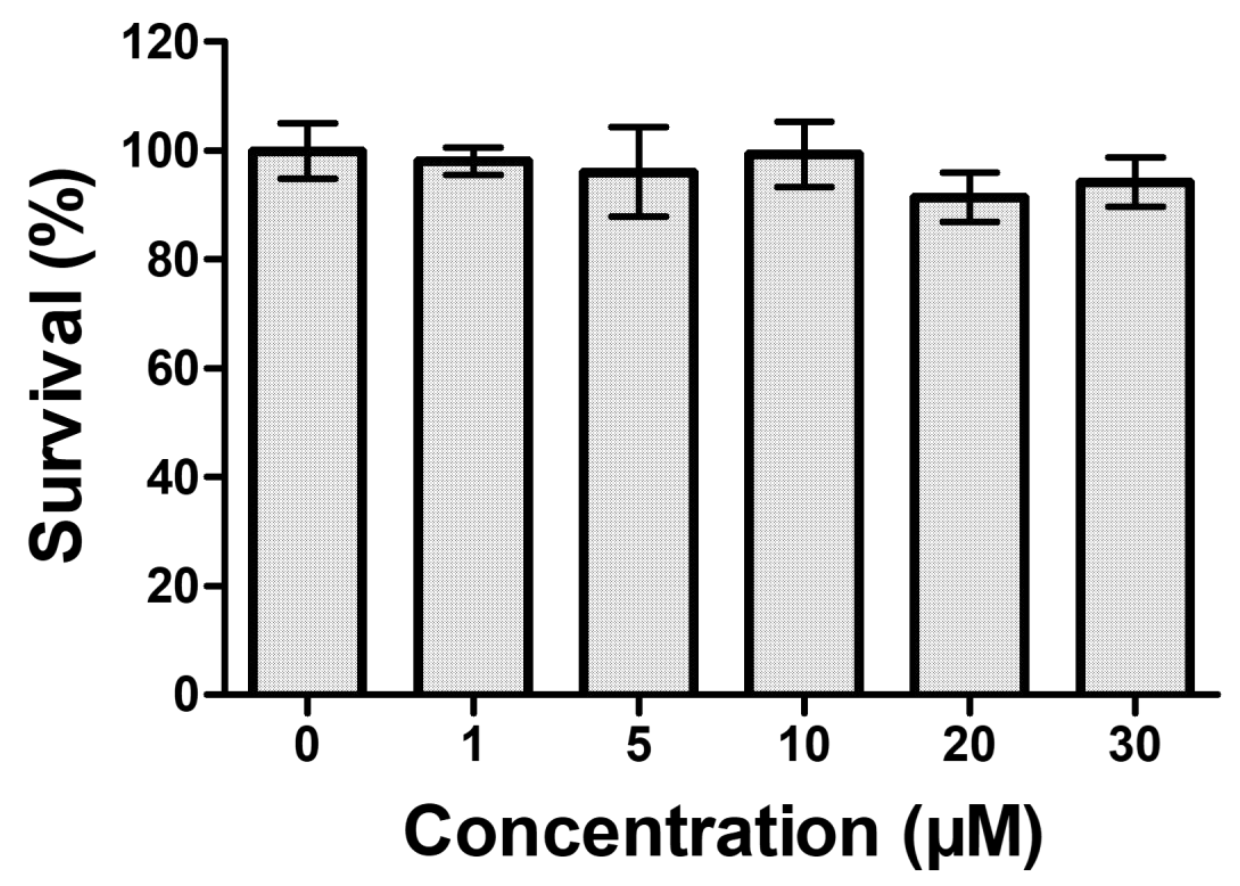

Figure S4. Cytotoxicity assays of YDGAL at different concentrations for Cos 7 cells.
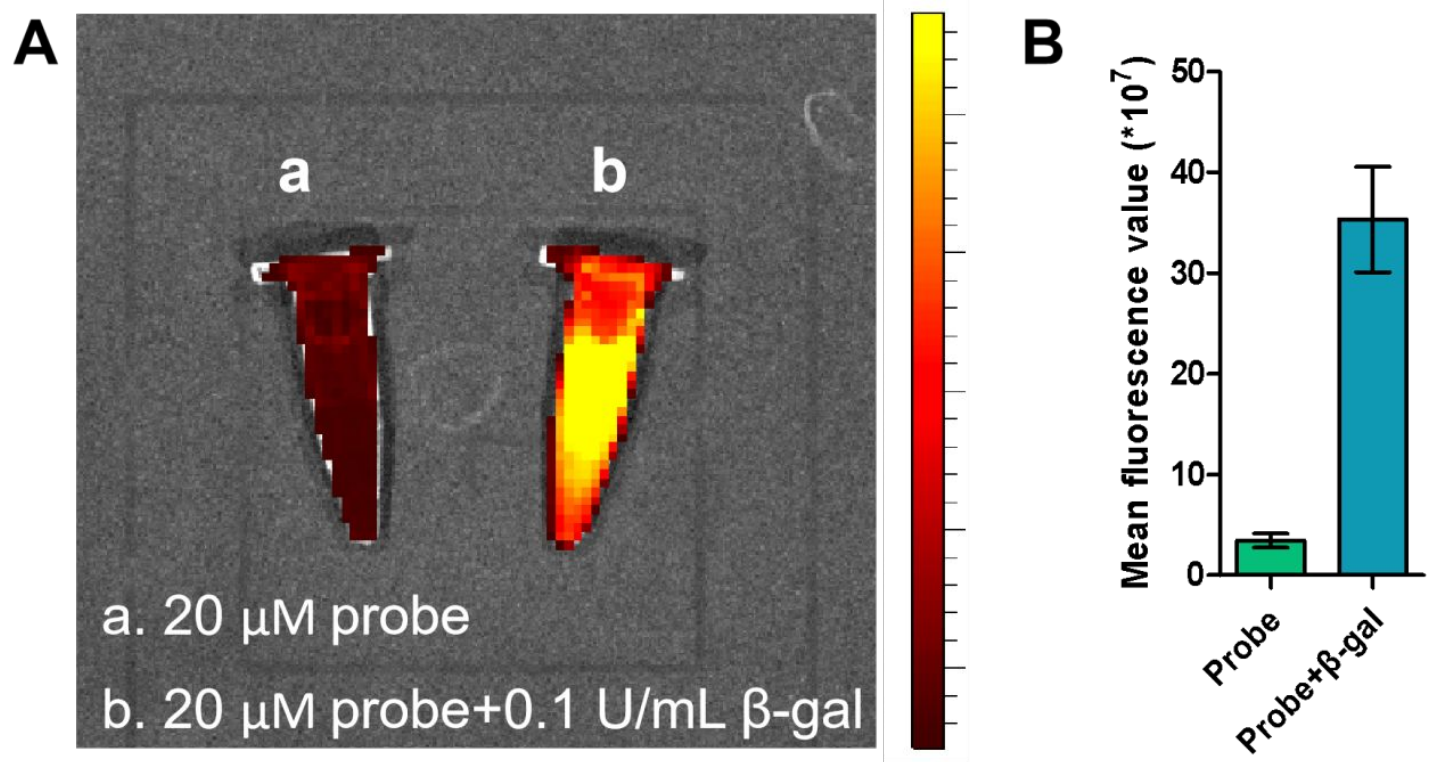

Figure S5. (A) Fluorescence imaging of $\beta$-gal in PBS with YDGAL $(20 \mu \mathrm{M})$. (B) Mean fluorescence value of A. 


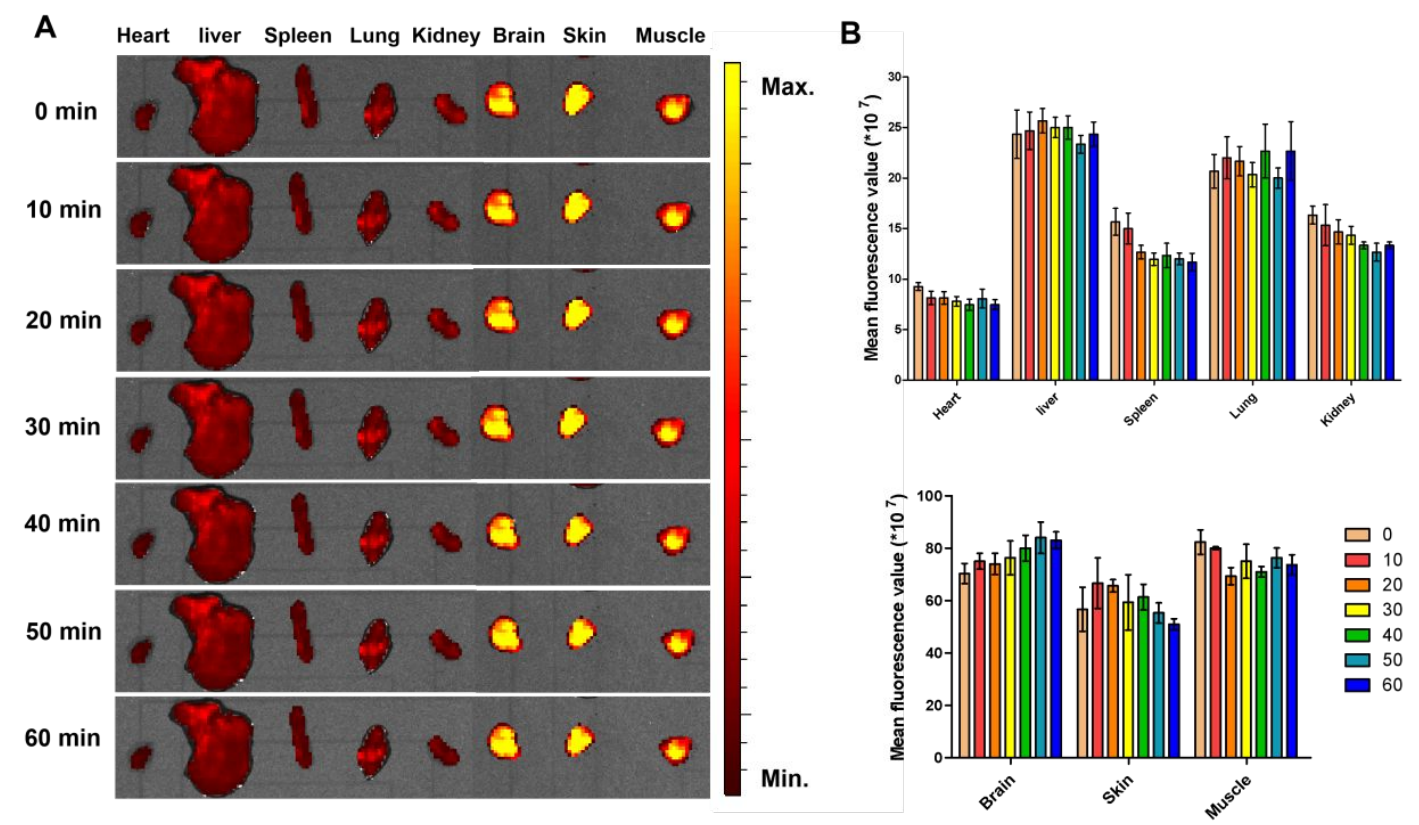

Figure S6. (A) Stable fluorescent imaging to $\beta$-gal in Heart, liver, Spleen, Lung, Kidney, Brain, Skin, and Muscle for 60 min. (After incubation with $100 \mu$ M YDGAL for 1 hour) (B) The relative fluorescence intensity of organs. Error bars represent standard deviation ( \pm S.D.) $, \mathrm{n}=3 . \lambda_{\mathrm{ex}}=500 \mathrm{~nm}, \lambda_{\mathrm{em}}=620 \mathrm{~nm}$. 
A

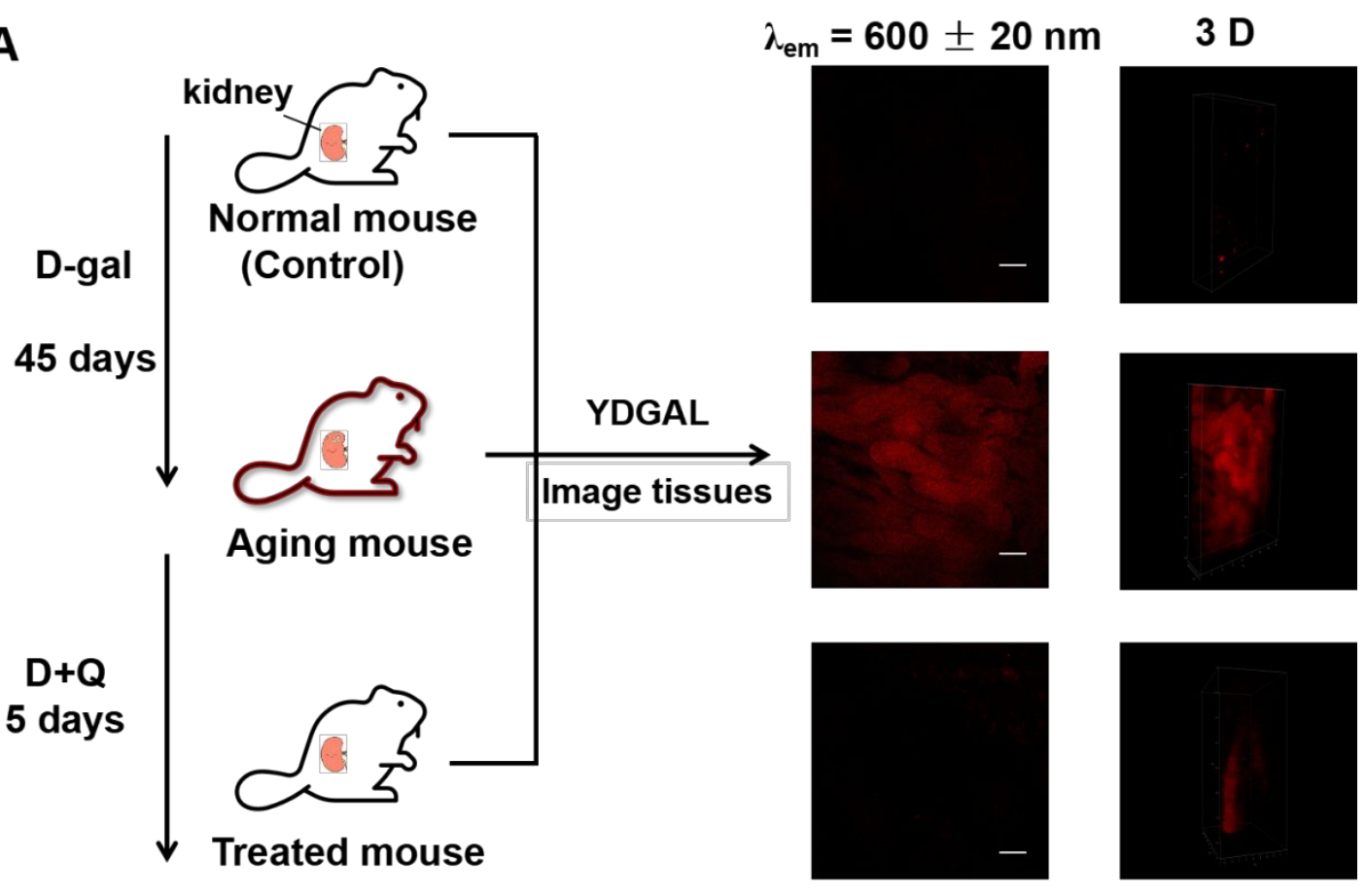

B

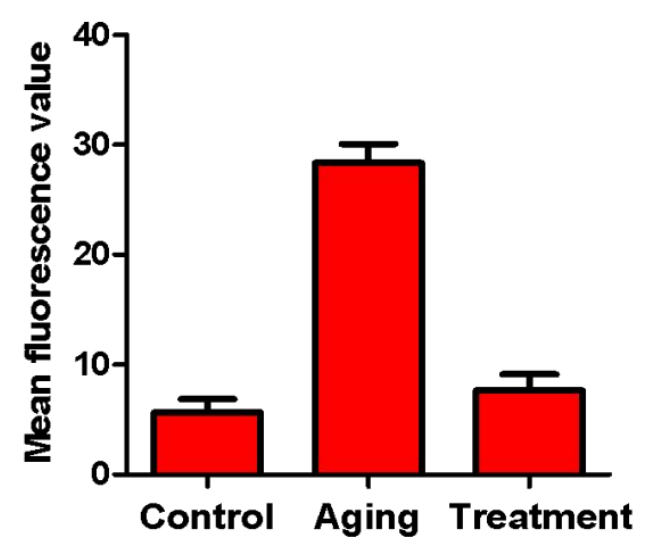

C

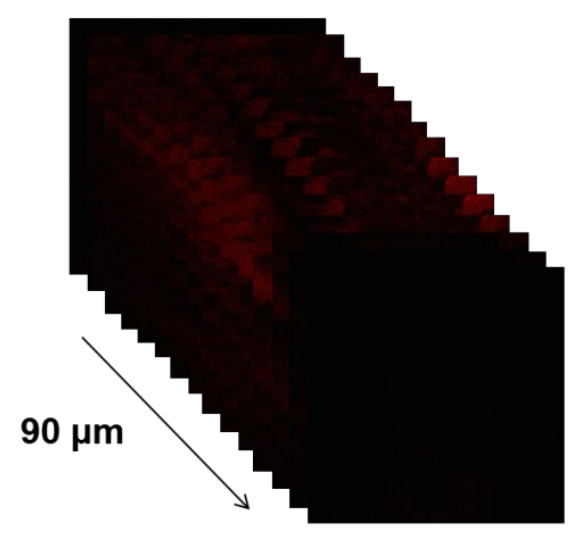

Figure S7. (A) Two-photon fluorescence images of kidney of normal (control), aging and the treated mouse incubated with YDGAL $(100 \mu \mathrm{M})$ for $0.5 \mathrm{~h}$ with a magnification of $10 \times$. (B) The relative fluorescent intensities of tissues. (C) Two-photon tissue fluorescent image of aging tissue. $\lambda_{\mathrm{ex}}=800 \mathrm{~nm}, \lambda_{\mathrm{em}}=580-620$ $\mathrm{nm}$. Scale bar $=30 \mu \mathrm{m}$. 
A

$$
\lambda_{\mathrm{em}}=600 \pm 20 \mathrm{~nm} \quad 3 \mathrm{D}
$$
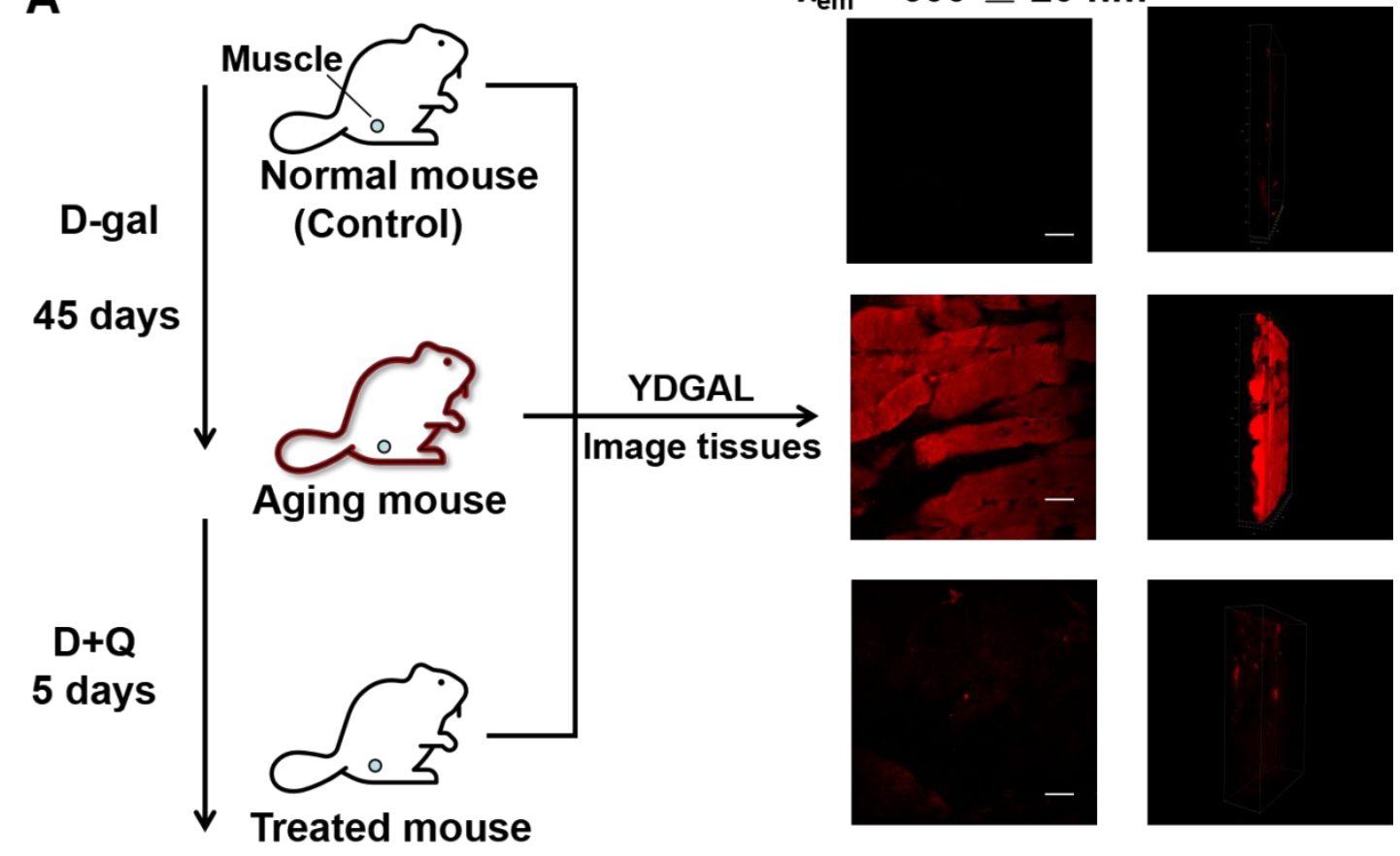

B
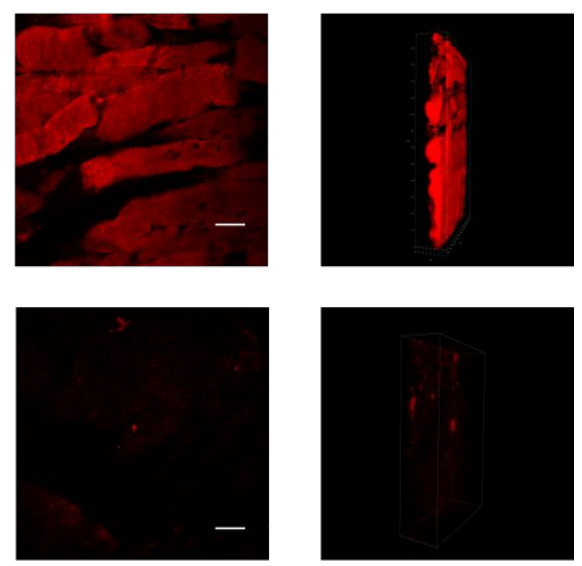

C
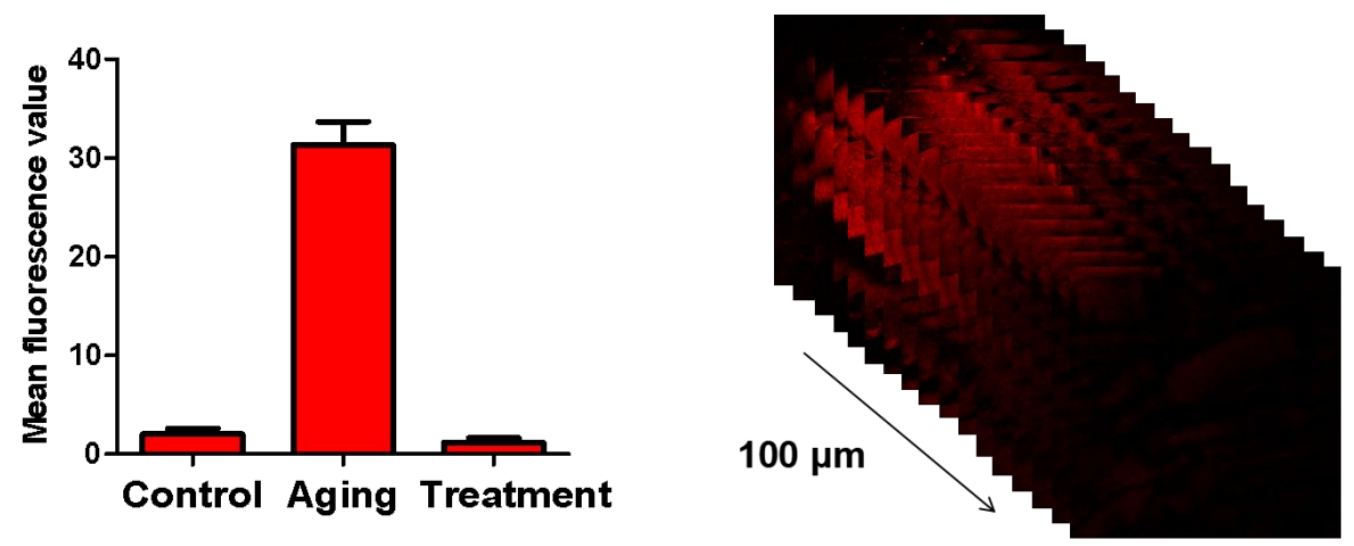

Figure S8. (A) Two-photon fluorescence images of muscle of normal (control), aging and the treated mouse incubated with YDGAL $(100 \mu \mathrm{M})$ for $0.5 \mathrm{~h}$ with a magnification of $10 \times$. (B) The relative fluorescent intensities of tissues. (C) Two-photon tissue fluorescent image of aging tissue. $\lambda_{\mathrm{ex}}=800 \mathrm{~nm}, \lambda_{\mathrm{em}}=580-620$ $\mathrm{nm}$. Scale bar $=50 \mu \mathrm{m}$. 


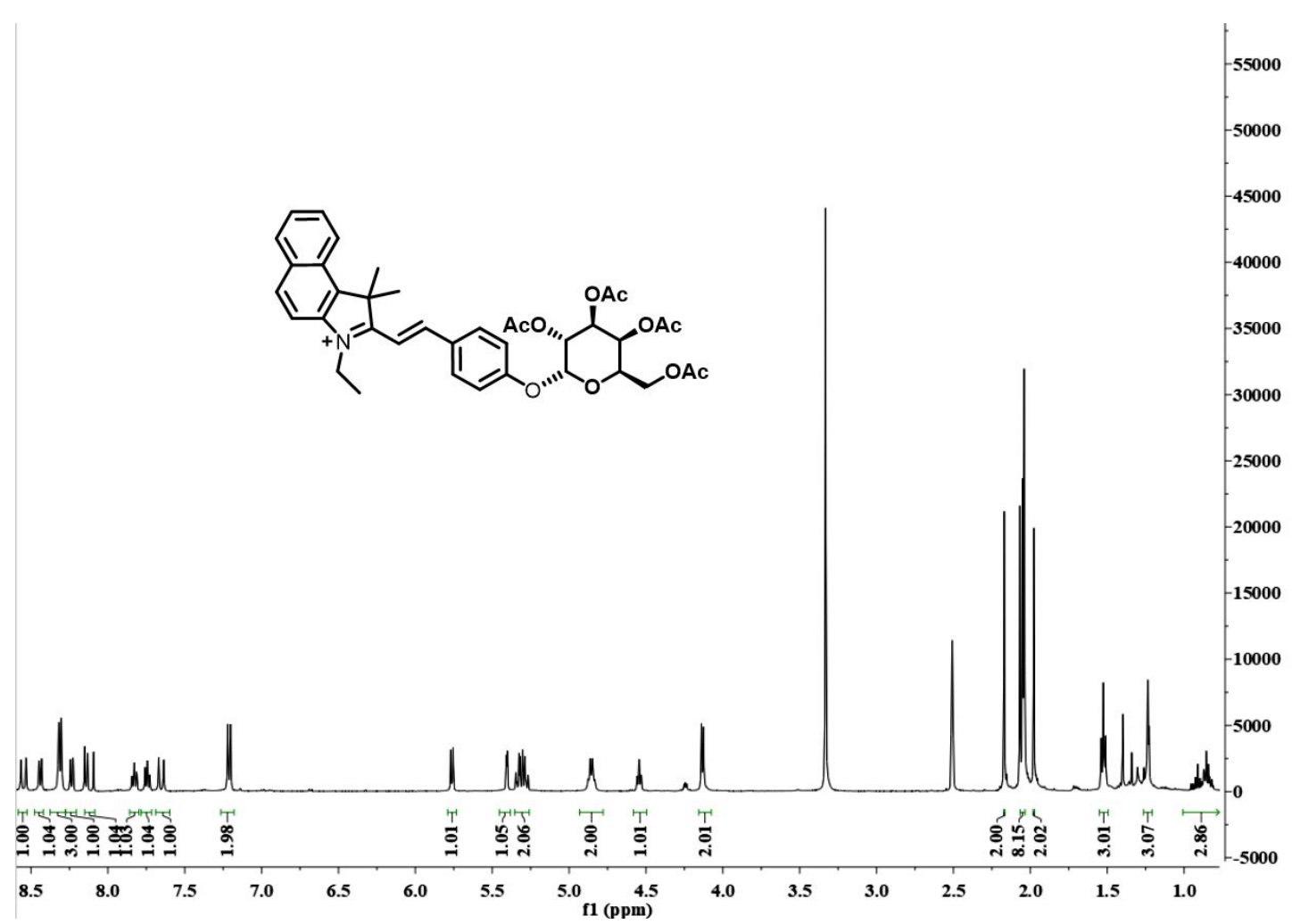

Figure S9. ${ }^{1} \mathrm{H}-\mathrm{NMR}\left(\mathrm{DMSO}-d_{6}\right)$ spectrum of Compound 3.

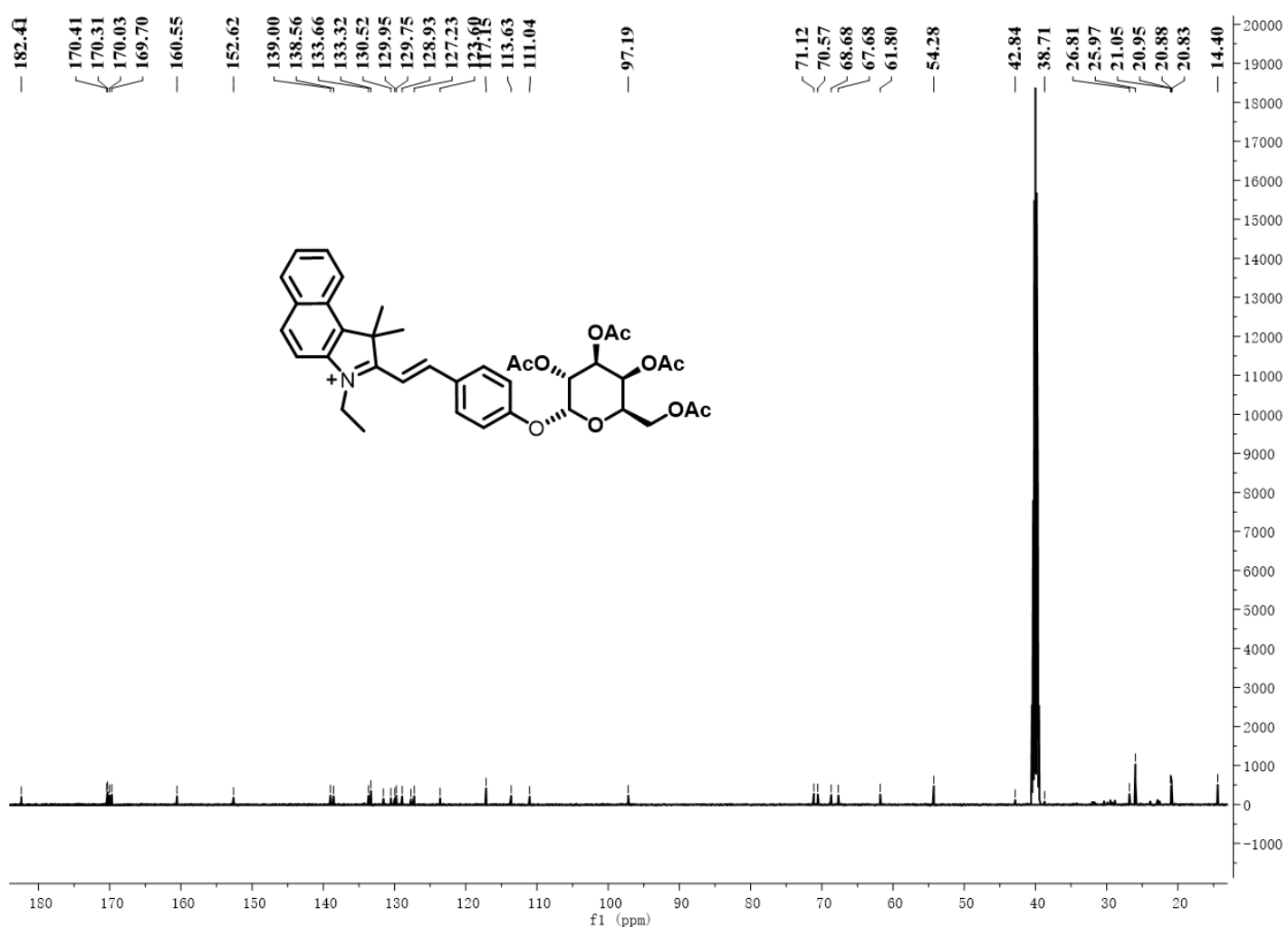

Figure S10. ${ }^{13} \mathrm{C}$ NMR (DMSO- $d_{6}$ ) spectrum of Compound 3. 


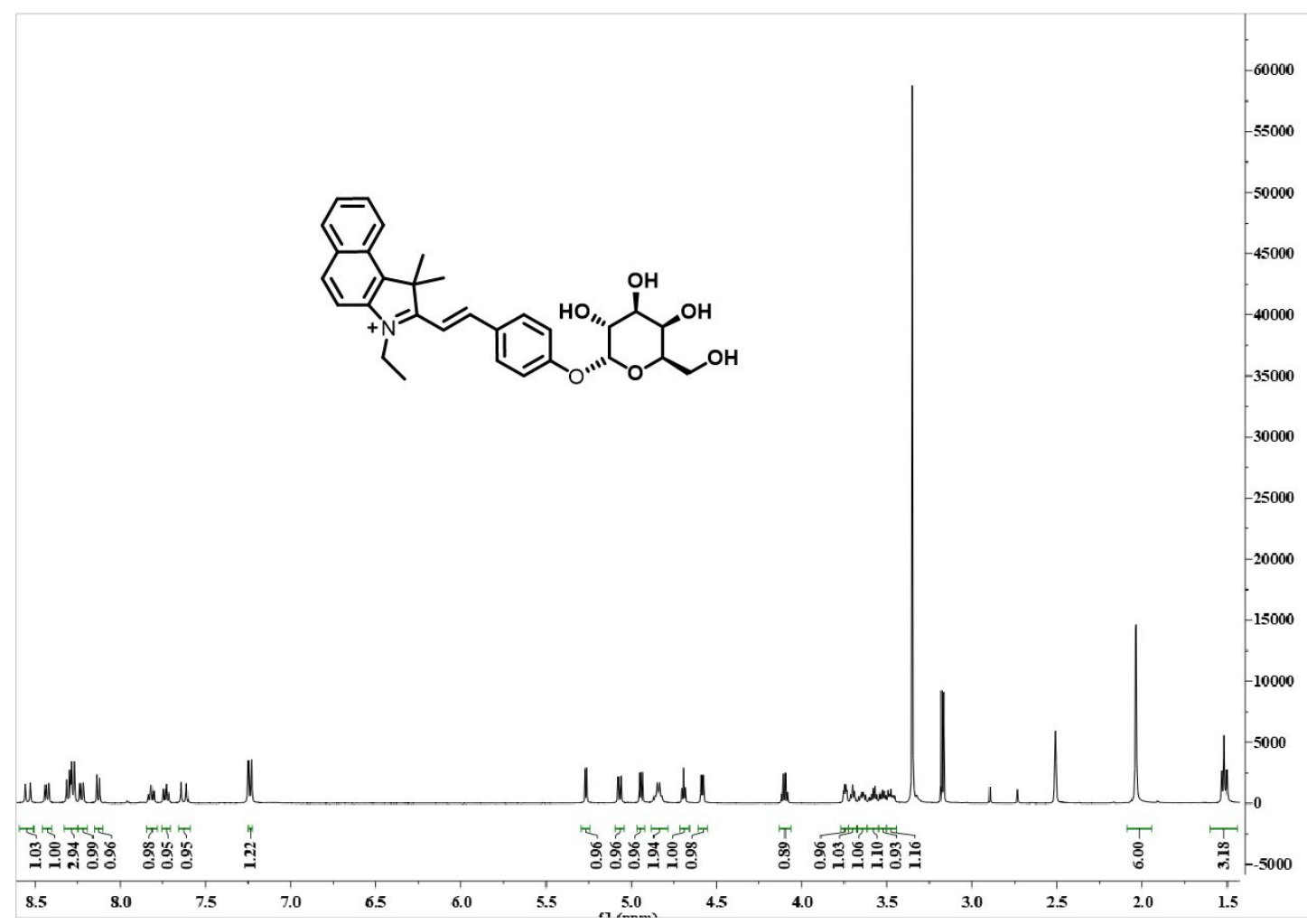

Figure S11. ${ }^{1} \mathrm{H}$ NMR (DMSO- $d_{6}$ ) spectrum of YDGAL.

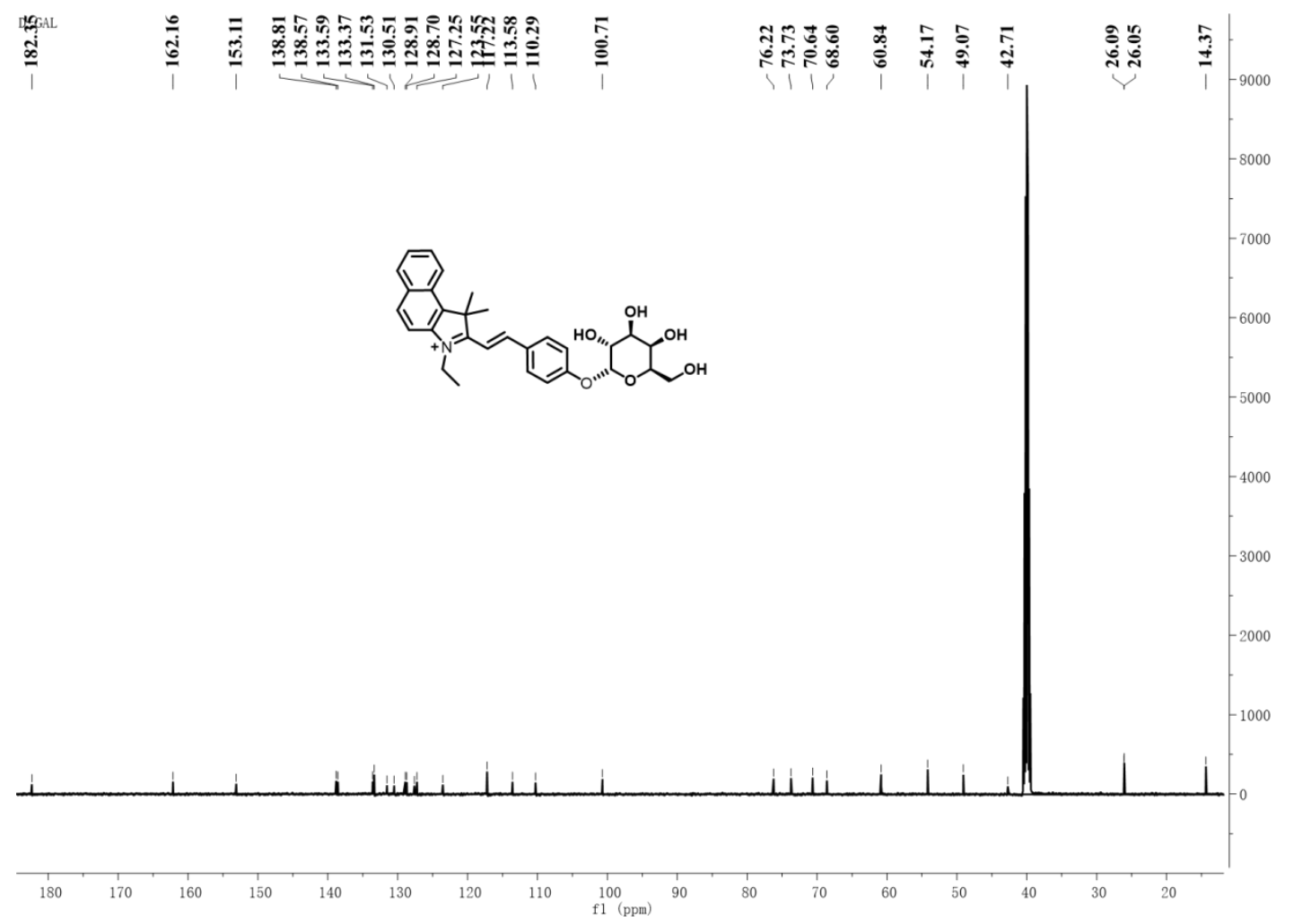

Figure S12. ${ }^{13} \mathrm{C}$ NMR (DMSO- $d_{6}$ ) spectrum of YDGAL. 


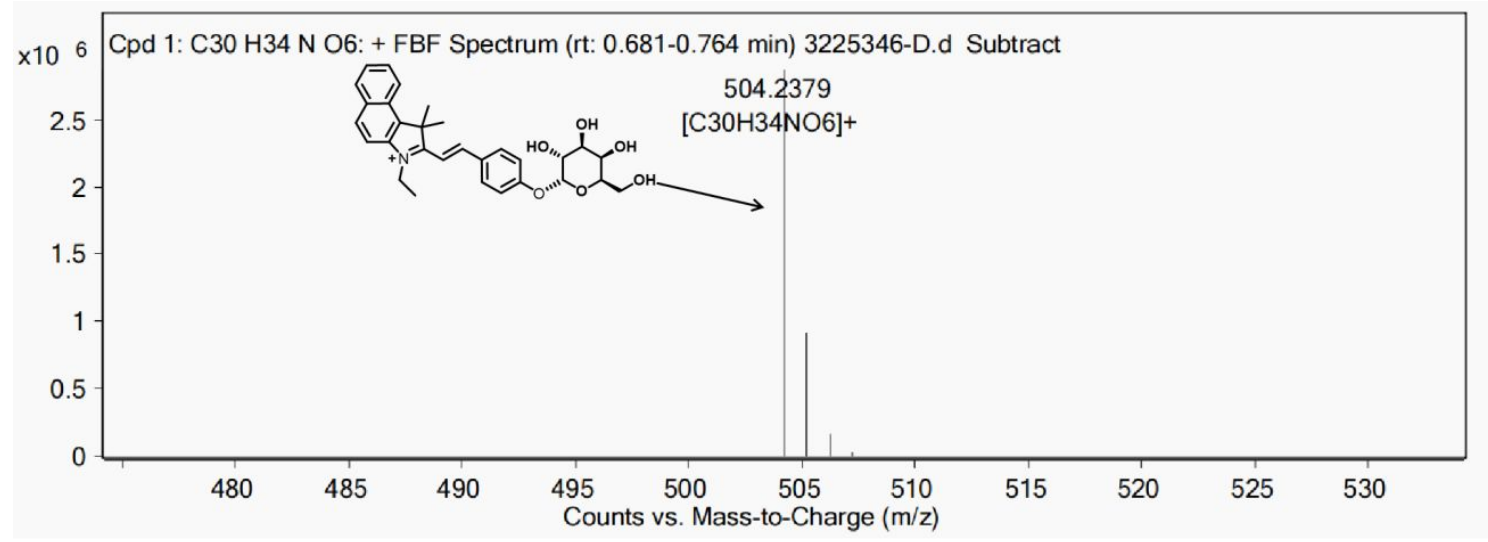

Figure S13. HRMS (ESI) spectrum of YDGAL, $\mathrm{M}^{+}$, 504.2386.

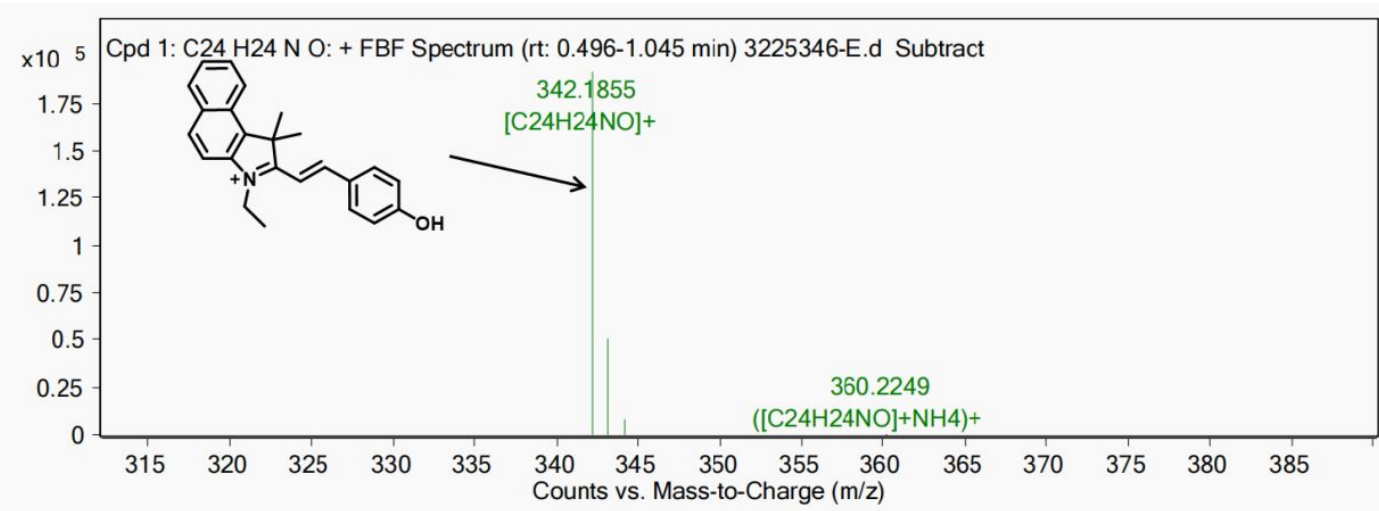

Figure S14. HRMS (ESI) spectrum of the reaction products of YDGAL with $\beta$-gal, $\mathrm{M}^{+}, 342.1858$. 


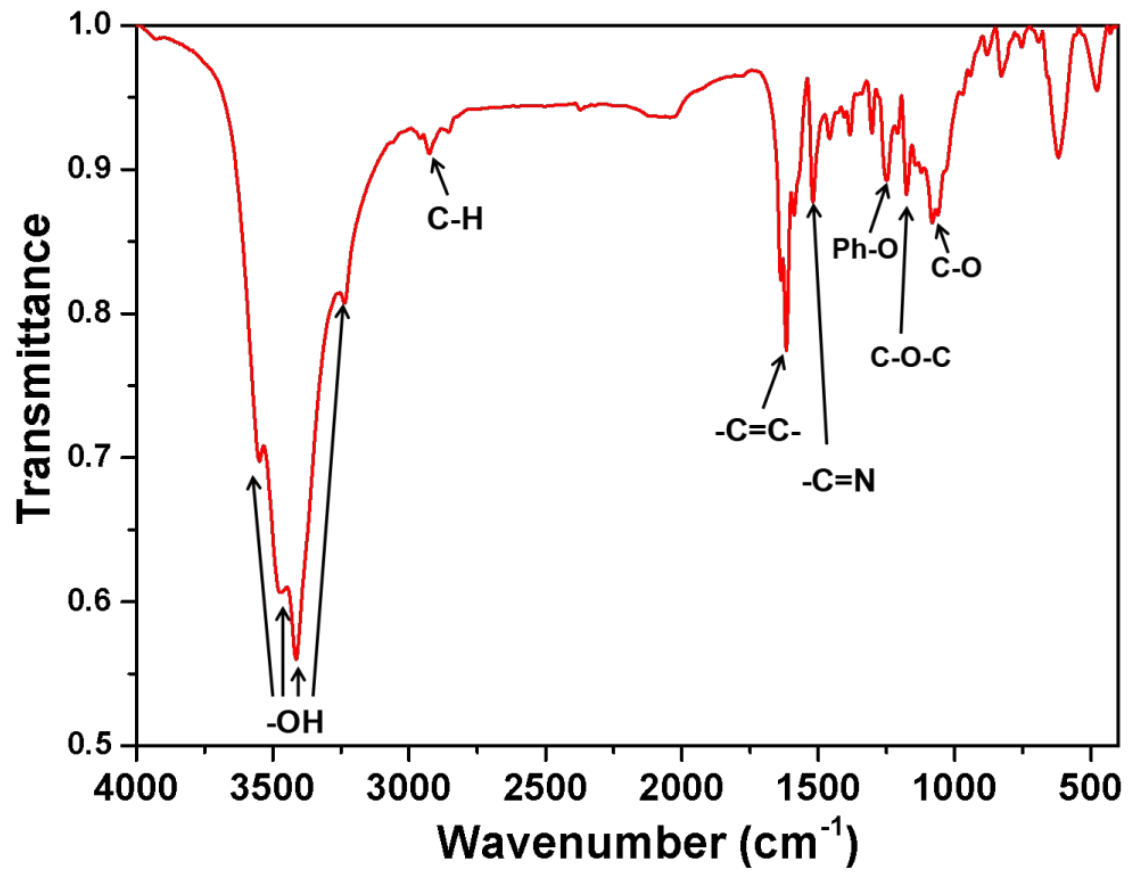

Figure S15. Infrared spectrum of the probe YDGAL. 


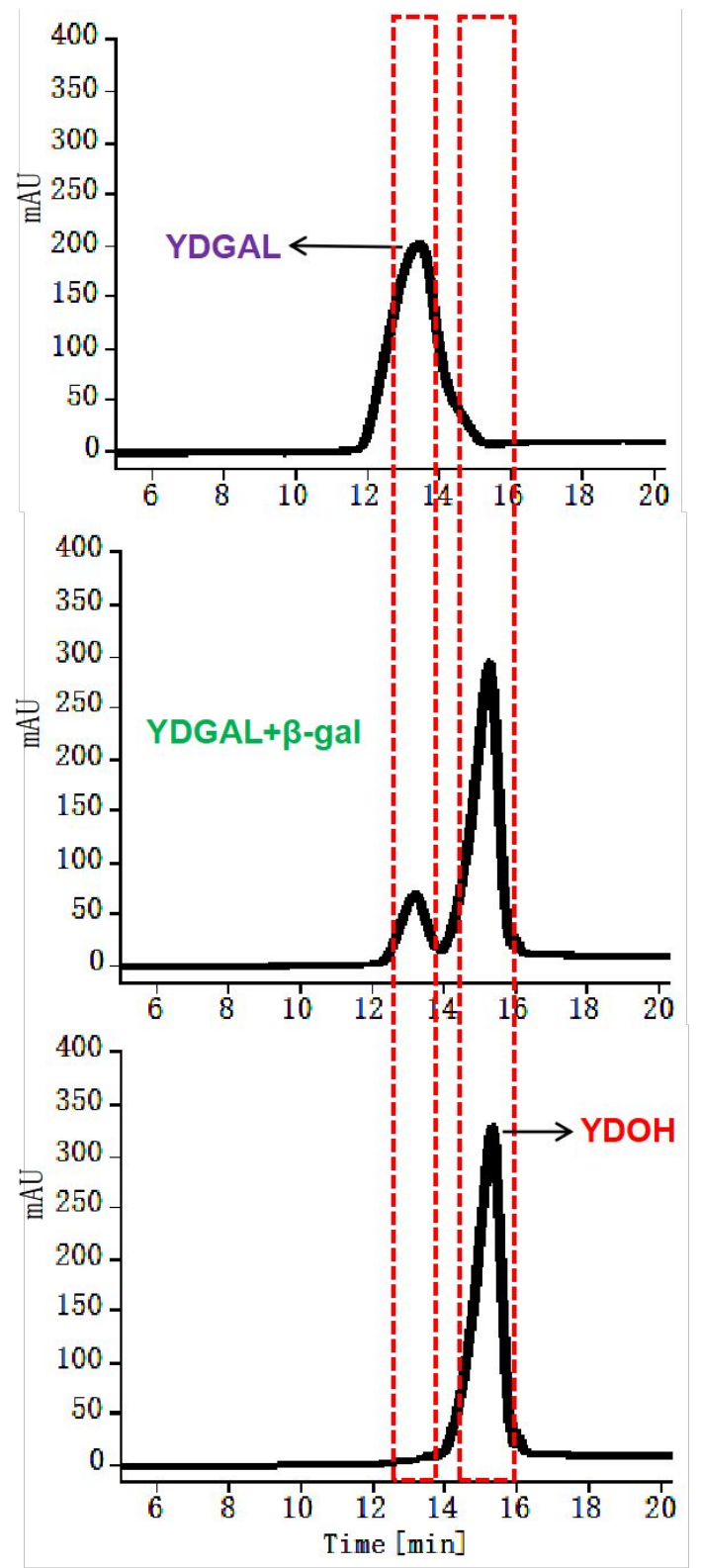

Figure S16. HLPC spectrum of YDGAL, YDGAL+ $\beta$-gal, and YDOH. 